\title{
Alkylation by Enamines for Synthesis of some Heterocyclic Compounds
}

\author{
Jasim A. Abdullah \\ Department of Chemistry \\ College of Education \\ Mosul University
}

(Received 25/9/2008; Accepted 13/4/2009)

\begin{abstract}
Compounds of 4-phenyl-3-butene-2-one (1) and 4-(4-chlorophenyl)-3-butene-2-one (2) were prepared by reaction of benzaldehyde or 4-chlorobenzaldehyde with acetone. Also 1,3-diphenyl-2-chloropropene-1-one (3) was synthesized from the reaction of benzaldehyde with 2-chloroacetophenone through Claisen-Shmidt condensation. The substituted $\Delta^{1(9)}$ octalone-2 $(4,5)$ was prepared by reaction of the compounds (1and2) with cyclohexanone through Michael addition followed by aldol condensation. Compounds $(4,5)$ were reacted with alkyl halide, as 2-chloroacetophenone or 1,3-diphenyl-2-chloropropene-1-one (3), via enamines formation which then hydrolyzed to give compounds (6-9). Compounds $(6,7)$ were reacted with hydrazine, urea and thiourea to afford compounds (10-15) .

The structures of all synthesized compounds were confirmed by available physical and spectral means .
\end{abstract}

Keywords : Enamines, Heterocyclic compounds.

\section{الاكلة بولمطة الأينامينك الثييد بهض المركبلت الحالفية غير المتجلنسة}

\section{الملغص}

مق تحضير المركبلت 4 فنيل -3 -بيوتين -2 -اون (1) و4 -(4 -كلوروفنل) -3 -بيوتين -2 -اون (2) من فاعل البزالديهيد أو 4 -كلوروالبززاليهيد مع المبيتون -

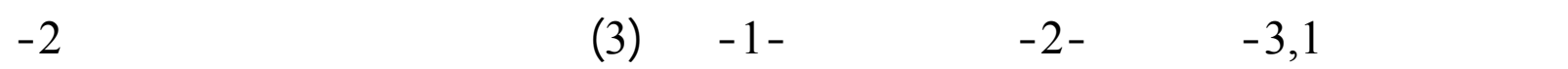

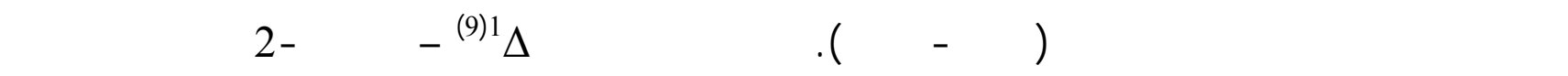

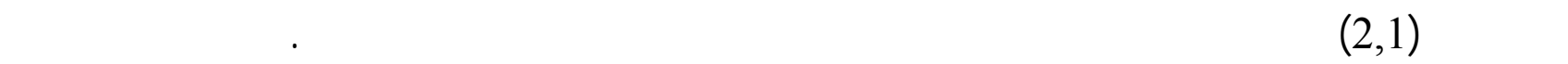

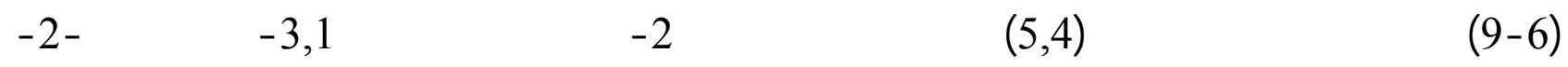

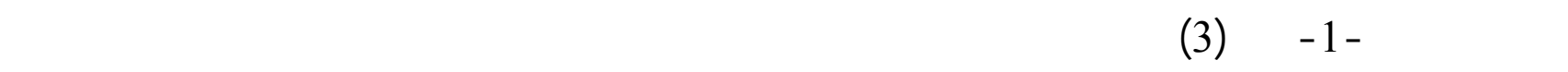

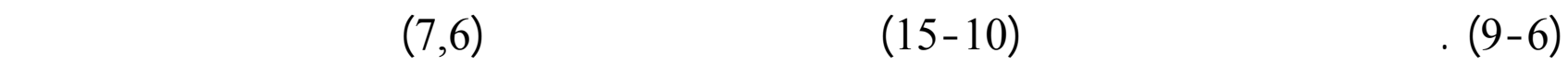
والثايوريا .شخصت المركبلت الناتجة بوسطة الطرايق الفيزياوية والتحليلات الطفية المتوفرة (UV , IR) بالإضفة إلى بعض الكثوفلت ألمختبريه . 


\section{INTRODUCTION}

In general, a compound that contains both a carbon-carbon double bond and a carbonoxygen double bond has properties that are characteristic of both functional groups (Morrison and Boyed, 1973). At the carbon-carbon double bond an unsaturated ester or unsaturated ketone undergoes electrophilic addition of acids and halogens, hydrogenation, hydroxylation and cleavage; at the carbonyl group it undergoes the nucleophilic substitution typical of an ester or the nucleophilic addition typical of a ketone.

$\alpha, \beta$-unsaturated carbonyl compounds, posses not only the properties of individual functional groups, but certain other properties besides. There are several general ways to make compounds of this kinds: the aldol condensation to make unsaturated aldehydes and ketones, dehydrohalogenation of halo acids and the Perkin condensation to make unsaturated acid. Aldol condensation are often used to close five- and six-membered rings, such ring closures generally take place with ease, even where a ketone condenses with a ketone. An important example is the Robinson annulation reaction (Jung, 1976; Takao, and Kobayashi, 1997; Hagiwara et al., 1994; Watson et al., 1995, Lejeune and Lallemand, 1991), which has often been used in the synthesis of steroids and terpens. In this reaction a cyclic ketone is converted to another cyclic ketone, with one additional six-membered ring containing a double bond. The substrate is treated with methyl vinyl ketone (or a simple derivative of methyl vinyl ketone) and a base (March, 1977). The enolate ion of the substrate adds to the methyl vinyl ketone in a Michael reaction to give a diketone which undergoes or is made to undergo an internal aldol condensation and subsequent dehydration to give the product.

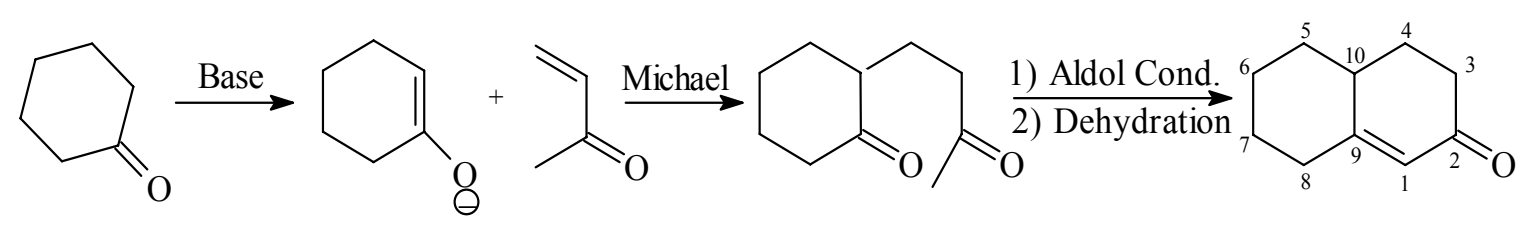

Stork enamine alkylation ,also known as the Stork-Enamine reaction, involves the addition of an enamine to an $\alpha, \beta$-unsaturated accepter in aprocess similar to the Michael reaction.(Mc Murry, 2003). The product is then hydrolyzed by an aqueous acid to produce a 1,5-dicarbonyl compound. The process: formation of an enamine from a ketone, addition of the enamine to an $\alpha, \beta$-unsaturated aldehyde or ketone and hydrolysis of the enamine back to a ketone. When the electrophile is an acyl halide a 1,3-diketone is formed (Stork acylation).The reaction is named after its inventor: Gelbert Stork.(March, 1985 ).As shown below: 


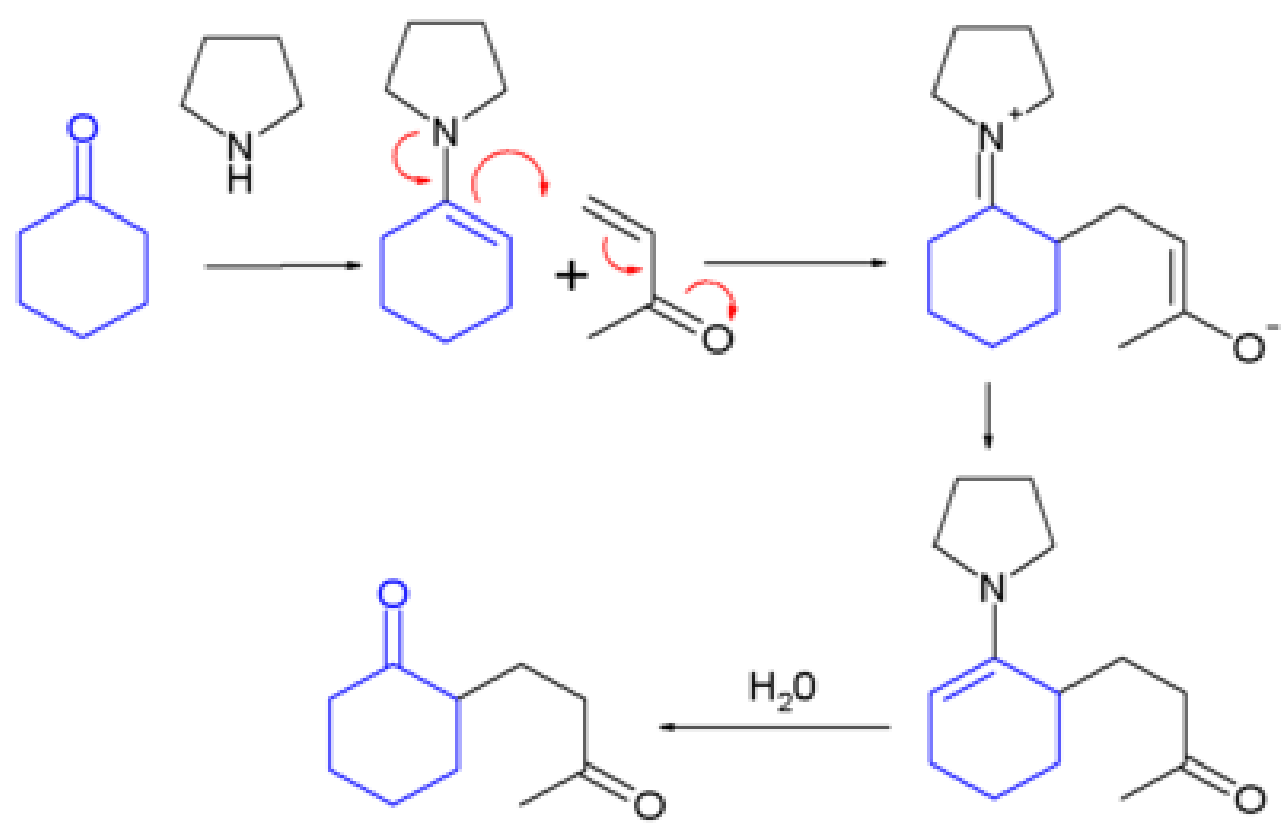

The compound $\Delta^{1(9)}$-Octalone-2 has been prepared by condensation of 4-diethylamino-2butanone with cyclohexanone; by condensation of 2-diethylaminomethylcyclohexanone with ethyl acetoacetate ( $\mathrm{Du}$ Feu, et al., 1937); by condensation of 4-oxo-1,1dimethylpiperidinium salts with 2-carbethoxycyclohexanone (Robert and Joseph, 1973); by the oxidation of $\alpha$-decalones (Zeiss and Martin, 1953); and by the reduction of 6methoxytetralin (Byong-Dong et al.,1997). In a general (Stork et al., 1963) base catalyzed reaction, substitution occurs on the more substituted center. It is now well established that 4aryl- ${ }^{1(9)}$-octalone-2 (4 and 5) is prepared from 4-aryl-3-buten-2-ones (1 and 2). Compounds (4 and 5) were alkylated with alkyl halide by enamines to form compounds (6-9) .

Chemical and instrumentation :

\section{EXPERIMENTAL}

All chemicals were purchased from Flucka and BDH chemical Ltd. The melting points were measured on Electrothermal 9300 Engineering LTD and were uncorrected . IR spectra were recorded on Infrared spectrophotometer Model Tensor 27, Bruker Co., Germany, using $\mathrm{KBr}$ disks. UV spectra were recorded on shimadzu Double-Beam spectrophotometer UV-210 A using chloroform as a solvent .

The theoretical calculations were computed using semi-empirical AM1 module in the CS chemoffice molecular modeling package. The data obtained from the minimized geometry were used for the theoretical calculations .

\section{Preparation of 4-aryl-3-buten-2-ones (1,2) (Vogle, 1956)}

A mixture of $(0.395$ mole $42 \mathrm{~g})$ of pure substituted benzaldehyde and $(1.09$ mole $80 \mathrm{ml})$ of pure acetone in a $250 \mathrm{ml}$. flask equipped with a shacked mechanical stirrer and dropping funnel was immerse in a cold water bath and $10 \mathrm{ml}$ of $10 \%$ of sodium hydroxide was added slowly from a dropping funnel; adjust the rate of addition so that the temperature remains between $25^{\circ}$ and $30^{\circ}$. The mixture was stirred or shacked mechanically at room temperature 
for a further 2 hours; alternatively securely stopper the flask and shake mechanically for the same period. Render the mixture just acidic to litmus paper by the addition of dilute hydrochloride acid, transfer to a separatory funnel, remove the upper organic layer, extract the lower aqueous layer with $20 \mathrm{ml}$ of benzene and add the extract to the yellow upper layer. Wash the latter with $20 \mathrm{ml}$ of water, and dry with anhydrous magnesium sulphate. Evaporate the benzene on a water bath. The solid was recrystallized from light petroleum ether (b.p. $40-60^{\circ}$ ) to give yellow crystals, (Table 1) .

\section{Preparation of 1,3-diphenyl-2-chloropropene-1-one (3) (Vogle, 1956) .}

A solution of $(22 \mathrm{~g})$ of sodium hydroxide in $(200 \mathrm{ml})$ of water and $(125 \mathrm{ml})$ of ethanol was placed in a flask provided with a mechanical stirrer, the flask was immersed in a bath of crushed ice. ( 0.43 mole $66.44 \mathrm{~g})$ of pure 2-chloroacetophenone and $(0.43$ mole $45.58 \mathrm{~g})$ of pure benzaldehyde were added with stirring. The temperature of the mixture was maintained at $\left(25^{\circ} \mathrm{C}\right)$ while a vigorous stirring was continued for $(15 \mathrm{~min})$. The product was filtered, washed with cold water until be neutral to litmus, then washed with ice-cold rectified spirit and finally recrystallized from ethanol to give white solid product (Table 1).

Table 1: Some physical properties and spectral data for compounds (1-3)

\begin{tabular}{|c|c|c|c|c|c|c|c|}
\hline \multirow{2}{*}{$\begin{array}{c}\text { Comp. } \\
\text { No. }\end{array}$} & \multirow{2}{*}{$\mathbf{X}$} & \multirow{2}{*}{ M.p ${ }^{\circ} \mathrm{C}$} & \multirow{2}{*}{$\begin{array}{c}\text { Yield } \\
\%\end{array}$} & \multicolumn{3}{|c|}{ IR $(\mathrm{KBr}) v \mathrm{~cm}^{-1}$} & \multirow{2}{*}{$\begin{array}{c}\mathrm{U} \cdot \mathrm{V} \\
\left(\mathrm{CHCl}_{3}\right) \\
\lambda \max \mathrm{nm}\end{array}$} \\
\hline & & & & $\mathrm{C}=\mathbf{O}$ & $\mathbf{C}=\mathbf{C}$ & $\mathrm{Ar}, \mathrm{C}=\mathrm{C}$ & \\
\hline 1 & & 42 & 65 & 1656 & 1560 & 1450,1550 & 335 \\
\hline 2 & $\mathrm{Cl}$ & $97-99$ & 85 & 1665 & 1580 & 146 & 330 \\
\hline 3 & $\ldots$ & $78-80$ & 95 & 1668 & 1590 & 1496,1579 & 332 \\
\hline
\end{tabular}

Preparation of 4-phenyl-4,4a,5,6,7,8-hexahydronaphthalen-2(3H)-one(4),4-(4chlorophenyl)-4,4a,5,6,7,8-hexahydronaphthalen-2(3H)-one (5) (Mc.Crae.,1984; Mahrwald, 2004; Nielsen; Houlihan, 1968).

A mixture of $(0.33$ mole $)$ of $(1$ or 2$),(0.33$ mole $31 \mathrm{ml})$ of cyclohexanone $(150 \mathrm{ml})$ of diethyl ether and $(300 \mathrm{ml})$ of $(0.1 \mathrm{~N})$ of sodium hydroxide was stirred in a bath of crushed ice for $(3 \mathrm{hr}$.). Render the mixture just acid to litmus paper by the addition of dilute hydrochloric acid. Transfer to a reparatory funnel and remove the aqueous layer . Dry the organic layer with a little anhydrous magnesium sulphate. Evaporate the ether and then the product was recrystallized from petroleum ether to give (4 or 5) as pale yellow crystals (Table 2,3) .

Preparation of 4-phenyl-3-(2-phenyl-2-oxoethyl)-4,4a,5,6,7,8-hexahydronaphthalen2(3H)- one(6),4- (4-chlorophenyl) -3-(2-phenyl-2-oxoethyl) -4, 4a, 5, 6, 7, 8hexahydronaphthalen-2(3H)-one(7),3-(1-oxo-1,3-diphenyl-2-propen-2-yl)-4-phenyl4,4a,5,6,7,8-hexahydronaphthalen-2(3H)-one( 8 ) and 3-(1-oxo-1,3-diphenyl-2-propen-2-yl)4-(4-chlorophenyl)-4,4a,5,6,7,8-hexahydronaphthalen-2(3H)-one Gottfried, 1955 ; Lampman, and Kritz, 1998).

Dissolve (3.2 gm) of 2-chloroacetophenone or 1,3-diphenyl-2-chloropropene-1-one (3) in $5 \mathrm{ml}$ of dry benzene. Add this solution to a mixture of $\left(1.5\right.$ mole) of 4 -aryl- $\Delta^{1(9)}-$ 
octalone-2 (4 or 5), (1.8 ml) of morpholine and $(1.5 \mathrm{gm})$ p-toluenesulfonic acid in $250 \mathrm{ml}$ of dry benzene. The reaction mixture is placed in a $500 \mathrm{ml}$ round-bottomed flask equipped with a water separator or under a reflux condenser protected by a calcium chloride drying tube. Separation of water begins with reflux and is complete after 5 hours. After the mixture is cooled to room temperature, $(2 \mathrm{gm})$ of sodium ethoxide is added to remove ( $\mathrm{p}$ toluenesulfonic acid) in the next add $(25 \mathrm{ml})$ of water. Attach a condenser and heat the mixture under reflux for 30 minutes to convert the enamine to the ketone, the benzene layer is separated and then benzene evaporated. The product was recrystallized from petroleum ether $\left(40-60{ }^{\circ} \mathrm{C}\right)$ to give compounds (6-9), (Table 2,3).

Preparation of 3,5-diphenyl-4,4a,5,5a,6,7,8,9-octahydrobenzo[g]cinnoline (10), 3-phenyl-5(4-chlorophenyl)-4,4a,5,5a,6,7,8,9-octahydrobenzo [g] cinnoline (11). (Valentine et al., 2005 , Zhong -Xia and Hua-Li, 2004).

Add (0.02 mole) of compounds (6 or 7$)$ to solution of hydrazine hydrate $(0.02$ mole $1 \mathrm{ml})$ in $25 \mathrm{ml}$ of ethanol and $(5$ drops) of conc. $\mathrm{HCl}$. The mixture was refluxed for $(30$ min.), after cooling the solid was filtered, washed with methanol and recrystallized from (1:2-water-ethanol) to give compounds (10 and 11), (Table 2,3).

Preparation of 4,6-diphenyl-5,5a,6,6a,7,8,9,10-octahydronaphtho[2,3-d][1,3]diazepin-2one(12) and 4-phenyl-6-(4-chlorophenyl)-5,5a,6,6a,7,8,9,10-octahydronaphtho[2,3d][1,3]diazepin-2-one (13). (New Kome, and Fishel, 1988 ; Kalirajan et al., 2009).

Dissolve ( 0.02 mole) of compound ( 6 or 7$)$ in $20 \mathrm{ml}$ of ethanol and then add to this solution ( 0.02 mole $1.2 \mathrm{gm})$ of urea . The mixture was refluxed for ( 72 hours), after cooling the solid was filtered, washed with ethanol and recrystallized from (1:2-water-ethanol) to give compounds (12 and 13), (Table 2,3).

Preparation of 4,6-diphenyl-5,5a,6,6a,7,8,9,10-octahydronaphtho[2,3-d][1,3]diazepin-2thione(14) and 4-phenyl-6-(4-chlorophenyl)-5,5a,6,6a,7,8,9,10-octahydronaphtho[2,3d][1,3]diazepin-2-thione(15). (Evelin, 1989).

Dissolve (0.02 mole) of compound (6 or 7) in $20 \mathrm{ml}$ of ethanol and then added to this solution $(0.02$ mole $1 . .52 \mathrm{gm})$ of thiourea. The mixture was refluxed for ( 1 hour) and then added $(5 \mathrm{ml})$ of pyridine and the reflux was continued for another ( 1 hour), after cooling the solid was filtered, and recrystallized from (1:2-water-ethanol) to give compounds (14 and 15), (Table 2,3). 
Table 2 : physical properties for compounds (4-15) .

\begin{tabular}{|c|c|c|c|c|}
\hline Compd. No. & $\mathbf{X}$ & $\mathbf{M . p}^{\mathbf{0}} \mathbf{C}$ & Color & Yield \% \\
\hline 4 & $-\mathrm{H}$ & $135-136$ & Pale yellow & 75 \\
\hline 5 & $-\mathrm{Cl}$ & $204-205$ & Pale yellow & 80 \\
\hline 6 & $-\mathrm{H}$ & $175-177$ & White & 65 \\
\hline 7 & $-\mathrm{Cl}$ & $219-221$ & White & 85 \\
\hline 8 & $-\mathrm{H}$ & $200-202$ & Green & 78 \\
\hline 9 & $-\mathrm{Cl}$ & $230-232$ & Green & 87 \\
\hline 10 & $-\mathrm{H}$ & $254-255$ & Yellow & 72 \\
\hline 11 & $-\mathrm{Cl}$ & $282-283$ & Yellow & 75 \\
\hline 12 & $-\mathrm{H}$ & $222-224$ & Brown & 62 \\
\hline 13 & $-\mathrm{Cl}$ & $260-261$ & Brown & 73 \\
\hline 14 & $-\mathrm{H}$ & $233-235$ & Yellow & 57 \\
\hline 15 & $-\mathrm{Cl}$ & $291-292$ & Yellow & 64 \\
\hline
\end{tabular}

\section{RESULTS AND DISCUSSION}

The structure of compounds $(1,2)$ were elucidated by ultra violet and infrared spectra (Table 1), which showed sharp peaks at $\left(1656,1665 \mathrm{~cm}^{-1}\right)$ due to carbonyl groups, a medium peak at $\left(1560,1580 \mathrm{~cm}^{-1}\right)$ due to $(\mathrm{C}=\mathrm{C})$ double bonds. Compound (3) was prepared by Claisen-Shmidt reaction. The spectral informations showed a sharp peak at $\left(1668 \mathrm{~cm}^{-1}\right)$ due to a carbonyl group, a medium peak at $\left(1590 \mathrm{~cm}^{-1}\right)$ due to $(\mathrm{C}=\mathrm{C})$ double bond (Sandler, and Karo, 1972). The U.V spectra of compounds (1-3) showed $\lambda \max$ at $(330-335 \mathrm{~nm})$ which indicated that conjugation was found between the $(\mathrm{C}=\mathrm{O})$ group and $(\mathrm{C}=\mathrm{C})$ group causing bathochromic shift (red shift) comparing with those which have no conjugation (starting materials) .

The reaction of compounds $(1,2)$ with cyclohexanone produced compounds $(4,5)$ respectively. The IR spectra of compounds $(4,5)$ showed sharp peaks at $\left(1710,1708 \mathrm{~cm}^{-1}\right)$ respectively, due to the carbonyl groups, other peaks at $\left(1605,1601 \mathrm{~cm}^{-1}\right)$ due to the double bonds. The U.V spectra showed a $\lambda \max$ at $(320,302 \mathrm{~nm})$ for compounds $(4,5)$.

Compounds (6-9) were synthesized from the reaction of compounds $(4,5)$ via enamines alkylation by 2-chloroacetophenone; by compound (3), and then hydrolysis of enamines compounds to form carbonyl compounds (6-9). These compounds were showed sharp peaks at (1665-1681 $\left.\mathrm{cm}^{-1}\right)$ (Parikh, 1985) due to the non cyclic carbonyl groups and sharp peaks at $\left(1696-1702 \mathrm{~cm}^{-1}\right)$ due to the cyclic carbonyl groups, a medium peaks at $\left(1590-1597 \mathrm{~cm}^{-1}\right)$ due to the cyclic double bonds and at $\left(1604,1597 \mathrm{~cm}^{-1}\right)$ due to the non cyclic double bonds for compounds $(8,9)$ respectively .

Compounds $(10,11)$ were synthesized from the reaction of compounds $(6,7)$ with hydrazine, the IR spectra showed sharp peaks at $\left(1625,1620 \mathrm{~cm}^{-1}\right)$ due to $(\mathrm{C}=\mathrm{N})$ group and $\left(1589-1590 \mathrm{~cm}^{-1}\right)$ due to the cyclic double bond for compounds $(10,11)$ respectively .

Compounds (12-15) were synthesized by the reaction of compounds $(6,7)$ with urea to give compounds $(12,13)$, or with thiourea to give compounds $(14,15)$ respectively. The IR 
spectra showed sharp peaks at $\left(1680,1674 \mathrm{~cm}^{-1}\right)$ due to the carbonyl groups for compounds $(12,13),\left(1175,1190 \mathrm{~cm}^{-1}\right)$ due to the $(\mathrm{C}=\mathrm{S})$ group for compounds $(14,15)$ respectively.

The range peaks at $\left(1617-1627 \mathrm{~cm}^{-1}\right)$ due to the $(\mathrm{C}=\mathrm{N})$ group and the range peaks at $\left(1587-1613 \mathrm{~cm}^{-1}\right)$ due to the cyclic double bond .

Table 3 : IR and Spectral data for Compounds (4-15).

\begin{tabular}{|c|c|c|c|c|c|c|c|c|c|}
\hline \multirow[b]{2}{*}{$\begin{array}{c}\text { Comp. } \\
\text { No. }\end{array}$} & \multirow[b]{2}{*}{$\mathbf{X}$} & \multicolumn{7}{|c|}{ IR $(\mathrm{KBr}) \mathrm{vcm}^{-1}$} & \multirow{2}{*}{$\begin{array}{c}\mathrm{U} . \mathrm{V} \\
\left(\mathrm{CHCl}_{3}\right) \\
\lambda \mathbf{m a x} \\
\mathbf{n m}\end{array}$} \\
\hline & & $\begin{array}{c}\mathrm{C}=\mathbf{O} \\
\text { Non } \\
\text { cyclic }\end{array}$ & $\begin{array}{l}\mathrm{C}=\mathrm{O} \\
\text { Cyclic }\end{array}$ & $\begin{array}{c}\mathrm{C}=\mathrm{C} \\
\text { Non } \\
\text { cyclic }\end{array}$ & $\begin{array}{c}\mathrm{C}=\mathrm{C} \\
\mathrm{Cycli} \\
\mathrm{c}\end{array}$ & $\mathbf{C}=\mathbf{N}$ & $\mathbf{C}=\mathbf{S}$ & $\begin{array}{c}\text { Ar, } \\
\mathbf{C}=\mathbf{C}\end{array}$ & \\
\hline 4 & $-\mathrm{H}$ & $\ldots$ & 1710 & $\ldots$ & 1605 & $\ldots$ & $\ldots$ & $\begin{array}{l}1451 \\
1494\end{array}$ & 320 \\
\hline 5 & $-\mathrm{Cl}$ & $\ldots$ & 1708 & $\ldots$ & 1601 & $\ldots$ & $\ldots$ & $\begin{array}{c}1491 \\
1540\end{array}$ & 302 \\
\hline 6 & $-\mathrm{H}$ & 1681 & 1700 & $\ldots$ & 1597 & $\ldots$ & $\ldots$. & $\begin{array}{l}1478, \\
1567 \\
\end{array}$ & 330 \\
\hline 7 & $-\mathrm{Cl}$ & 1679 & 1696 & $\ldots$ & 1591 & $\ldots$ & $\ldots$ & $\begin{array}{l}1510, \\
1570\end{array}$ & 328 \\
\hline 8 & $-\mathrm{H}$ & 1669 & 1702 & 1604 & 1593 & $\ldots$ & $\ldots$ & $\begin{array}{l}1456, \\
1583\end{array}$ & 345 \\
\hline 9 & $-\mathrm{Cl}$ & 1665 & 1699 & 1597 & 1590 & $\ldots$ & $\ldots$ & $\begin{array}{l}1500, \\
1586\end{array}$ & 337 \\
\hline 10 & $-\mathrm{H}$ & $\ldots$ & $\ldots$ & $\ldots$ & 1589 & 1625 & $\ldots$ & $\begin{array}{l}1470, \\
1577\end{array}$ & 370 \\
\hline 11 & $-\mathrm{Cl}$ & $\cdots$ & $\cdots$ & $\cdots$ & 1590 & 1620 & $\ldots$. & $\begin{array}{l}1500, \\
1576\end{array}$ & 381 \\
\hline 12 & $-\mathrm{H}$ & $\ldots$ & 1680 & $\ldots$ & 1613 & 1628 & $\ldots$ & $\begin{array}{l}1490, \\
1570 \\
\end{array}$ & 384 \\
\hline 13 & $-\mathrm{Cl}$ & $\ldots$ & 1674 & $\ldots$ & 1590 & 1617 & $\ldots$ & $\begin{array}{l}1509, \\
1580 \\
\end{array}$ & 380 \\
\hline 14 & $-\mathrm{H}$ & $\ldots$ & $\ldots$ & $\ldots$ & 1595 & 1625 & 1175 & $\begin{array}{l}1495 \\
1575\end{array}$ & 390 \\
\hline 15 & $-\mathrm{Cl}$ & $\cdots$ & $\cdots$ & $\cdots$ & 1587 & 1627 & 1190 & $\begin{array}{c}1505 \\
1580\end{array}$ & 394 \\
\hline
\end{tabular}



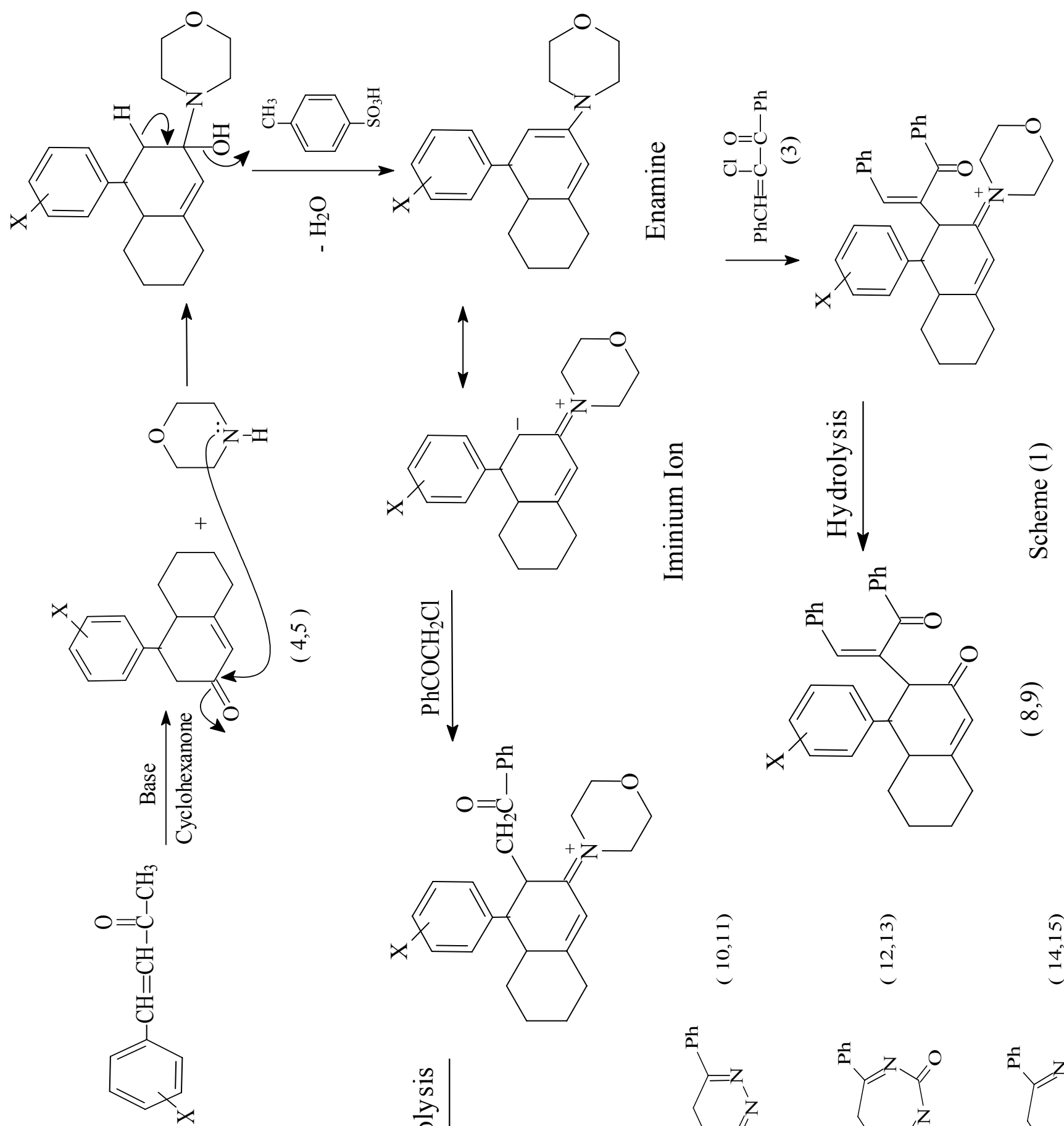

長
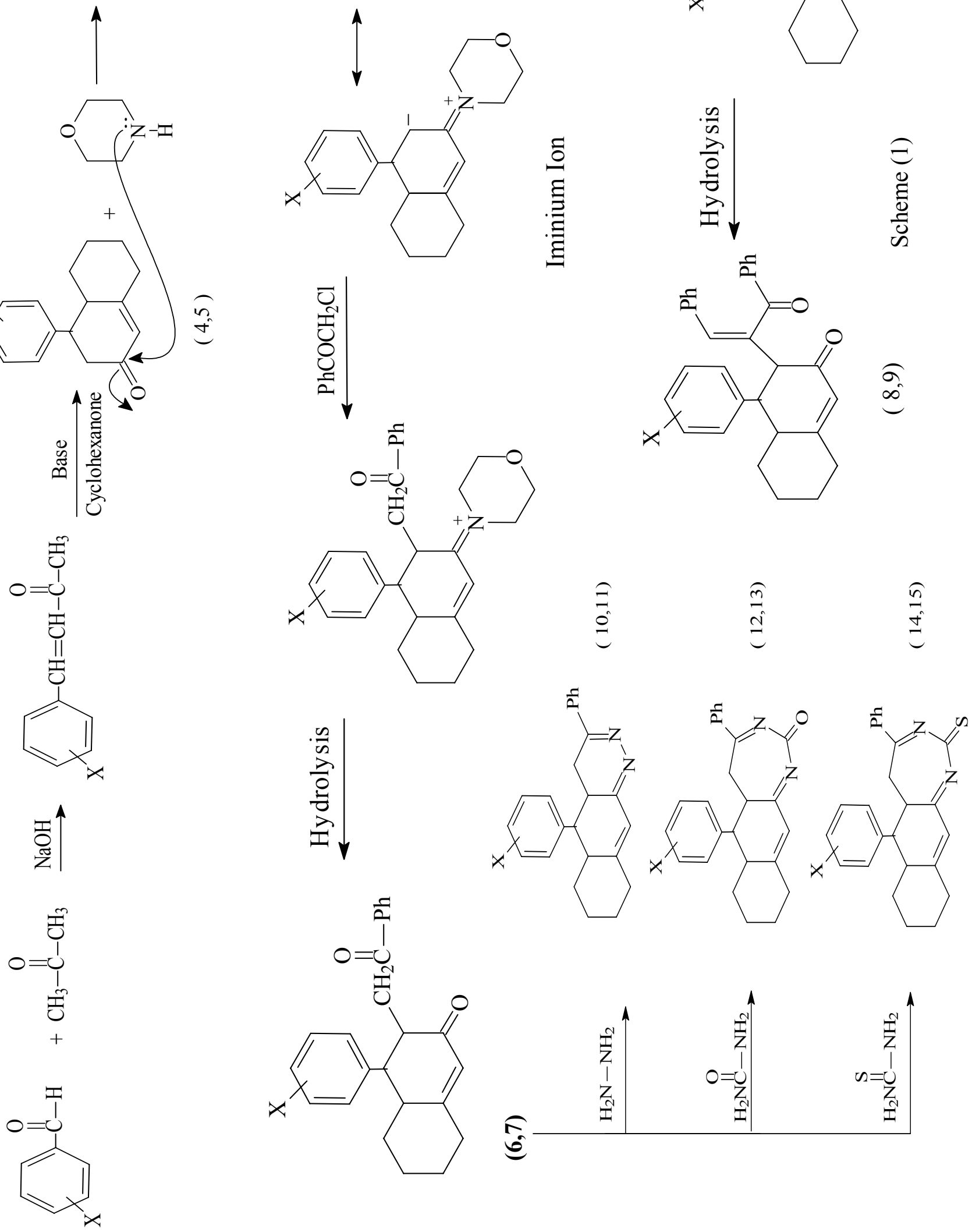


\section{REFERENCES}

Byong-Don Chong-Il Ji.; Seong-Soo, Oh.; Jae-Deuk Yang ; Woonphil Baik, and Sangho Koo, 1997. Highly Efficient Synthesis of Methyl-substituted Conjugate Cyclohexenones. J.Org. Chem. Soc. 62(26), pp. 9323-9325 .

Du Feu, E. C.; McQuillin, F. J. and Robinson R., 1937. Robinson Annelation Reaction. J. Chem. Soc. 53 p.

Evelin, B. M., 1989. Synthesis of some new Heterocyclic Compounds with Expected Potential Biological Activity. Journal of Islamic Academy of Science. 2:4.pp. 237-240.

Hagiwara, H.; Inoue, K. and Uda, H., 1994. Synthesis of Diterpene Clerodane. Tetrahedron Lett. 35: 8189p.

Jung, M. E., 1976. Areview of Annulation. Tetrahedron, 32: pp.3-31.

Kalirajan, R.; Sivakumar, S. U.; Jubie, S.; Gowramma, B. and Suresh, B., 2009. Synthesis and Biological Evaluation of some Heterocyclic Derivatives of Chalcones. International Journal of Chem. Tech. Research. Vol.1, No.1: pp.2734 .

Lampman, P. D. and Kritz, G. M., 1998. Organic Laboratory Techniques. 1st Ed. Harcourt Brace and company .

Lejeune, J. and Lallemand, J. Y., 1991. Synthesis Enantioselective of Substrate Decalines. Tetrahedron Lett. $32: 2621 \mathrm{p}$.

Mahrwald, R., 2004. Modern Aldol Reactions. Weinheim, Germany: Wiley-VCH Velarg Gmb H and Co. K Ga A. Vol.1 and 2. pp. 1218-1223

March, J., 1977. Advanced Organic Chemistry: Reactions, Mechanisms and Structures. 2nd Ed. Mc Graw-Hill Inc., New York, 852 p.

March, J., 1985. Advanced Organic Chemistry: Reactions, Mechanisms and Structures.

3 rd Ed. New York. Wiley, ISBN 0-471-85472-7

McCrae, W., 1984. Basic organic reactions. (translated). pp.121-122.

McMurry, J., 2003-03-21. (Hard cover). Organic chemistry. 6th Ed Belmont, CA: Thomson-Brooks/ Cole. ISBN 0-534-38999-6.

Morrison, T. and Boyed, N., 1973. Organic Chemistry. 3rd Ed Allyn and Bacon, Inc., New York, pp. 865-867.

Natelson, S. and Gottfried, S., 1955. Organic Synthesis. Coll. Vol. 3: 381 p.

New kome, G. R. and Fishel, D. L., 1988. Preparation of Hydrazone: Acetophenone Hydrazone. Org. Synth. Coll. Vol. 6: 12 p.

Nielsen, A. T. and Houlihan, W. J., 1968. Organic Reactions. 16 : pp. 1- 438.

Parikh, V. M., 1985. Absorption Spectroscopy of Organic Molecules. (translated) pp.185-199.

Robert, L. Augustine and Joseph, A. Caputo, 1973. $\Delta^{1(9)}$-octalone-2. Org. Synth. coll. Vol. 5: $869 \mathrm{p}$.

Sandler, S. R. and Karo, W., 1972. Organic Functional Group Preparation. Vol. 3: pp. 372-381.

Stork, G.; Brizzolara, A.; Landesman, H.; Szmuszkovicz, J. and Terrell, R., 1963. Enamines in Organic Synthesis. J. Am. Chem. Soc., 85: 207p.

Takao, K. and Kobayashi, S., 1997. The Aminal Motif of Zoanthamines. Tetrahedron Lett. , $38: 6685$ p. 
Valentine, G. Nenajdenko; Vasily, N. Korotchenko, Alexey, V. Shastin and Elisabeth, S. Balenkova., 2005. Conversion of Arylalkylketone into Dichloroalkene. Organic Synthesis, Vol. 82: 93p.

Vogle, A., 1956. Practical Organic Chemistry., 3rd Edn. Longman, London, 716 p.

Watson, A.; Park, K.; Wiemer, D. F. and Scott, W. J., 1995. Synthesis of Arenarone. J. Org. Chem., $60: 5102 p$.

Zeiss, H. H. and Martin, W. B., P. Jr., 1953. Oxidation of $\alpha$-Decalones. J. Am. Chem. Soc., 75: 5935p.

Zhong-Xia, W. and Hua-Li, Qin., 2004. Solventless Synthesis of Pyrazole Derivatives. Green Chem. , 6: pp. 90-92. 